\title{
Thermal Stability Study of S-Se Amorphous Compounds
}

\author{
L.A. Wahab*, M.B. El-Den and M.S. Youssef \\ *National Center for Radiation Research and Technology, Cairo, Egypt \\ Physics Department, Faculty of Science, Ain Shams University \\ Cairo, Egypt
}

\begin{abstract}
Amorphous selenium containing different concentrations of sulphur (0-5 at.\%) has been prepared by quenching the melt in air. The compositional dependence of density, hardness, specific heat, glass forming tendency as well as crystallization enthalpy have been measured, and the correlation between the obtained data and the chemical binding has been discussed. A cyclic scanning technique has been used to investigate the thermally induced phase during two consecutive heating-cooling cycles covering the temperature range $T_{g}-T_{m}$. The activation energy of crystallization using non-isothermal technique (DSC) has been determined and discussed.
\end{abstract}




\section{Introduction}

Chalcogenide glasses exhibits unique IR transmission and electrical properties that make these glasses useful for several potential applications such as threshold switching, memory switching, inorganic photoresistes, lenses for IR transmission and detection and optical waveguide for welding as well as surgery [1-3].

The nature of glass structure and thermal stability are important problems for the application of glasses. The differential scanning calorimetry (DSC) method have been widely used to determine the glass forming ability of compositions as well as for studying non-isothermal transformation kinetics. This work deals with studying the effect of addition of $S$ on the density, hardness, specific heat, and kinetics of crystallization of S-Se alloys. DSC is known to demonstrate with ease the characteristic difference between a structurally stable material (exhibiting switching phenomena) and a reversible material (exhibiting memory phenomena). For this study the effects of heating and cooling on both the exothermic as well as endothermic peaks were examined for these chalcogenide glasses.

\section{Experimental Technique}

The investigated samples with composition $\mathrm{SSe}_{\mathrm{x}}$, where $20 \leq \mathrm{x} \leq 40$, were synthesized by the conventional method of heating the constituents (all of 99.999\% purity) in sealed Pyrex tubes evacuated up to $10^{-4}$ torr. The sealed tubes were kept in a furnace at $350^{\circ} \mathrm{C}$ for $2 \mathrm{hrs}$ and was occasionally rocked to ensure homogenization. The melt was then quenched in air.

Thermal analysis experiments were carried out in the DSC-50 Shimadzu instrument. The experiments was elaborated at heating rates of 2 and $15^{\circ} \mathrm{C} /$ min under an inert atmosphere and referenced to $\alpha-\mathrm{Al}_{2} \mathrm{O}_{3}$ powder.

Hardness of the examined compositions has been measured using Shimadzu microhardness tester. The load and loading periods were 25 grams and 10 seconds for all samples, respectively. For every sample the measurements was repeated at least 10 times, the deviation in the calculated values did not exceed $2 \%$.

\section{Results and Discussion \\ 1-Phase Transitions}

Figure (1) shows typical DSC traces of freshly prepared $\mathrm{SSe}_{\mathrm{x}}$ glasses $(x=20,30 \& 40)$ taken at constant heating rate $15^{\circ} \mathrm{C} / \mathrm{min}$ (run a). In this figure, the endothermic due to the glass transition $\left(\mathrm{T}_{\mathrm{g}}\right)$ are observed at temperatures ranging from $52-56{ }^{\circ} \mathrm{C}$ according to $\mathrm{S}$ content. Above $\mathrm{T}_{\mathrm{g}}$ an exothermic due to crystallization $\left(\mathrm{T}_{\mathrm{p}}\right)$ occurred in the range $78.3-88.7^{\circ} \mathrm{C}$. Following $\mathrm{T}_{\mathrm{p}}$ an 
endothermic peak due to the melting $\left(\mathrm{T}_{\mathrm{m}}\right)$ occurred in the range 210.2223.6Q ${ }^{\circ} \mathrm{C}$. Table (1) gives the observed transition temperatures for the investigated samples.

The crystallization enthalpy $\left(\Delta \mathrm{H}_{\mathrm{c}}\right)$ was calculated using the relation, $\Delta \mathrm{H}_{\mathrm{c}}=\mathrm{kA}$, where $\mathrm{A}$ is the area of the crystallization exothermic and $\mathrm{k}$ is the calibration constant of the instrument that is given by, $\mathrm{k}=\Delta \mathrm{HM} / \mathrm{A}$ where $\Delta \mathrm{H}$ is the amount of the energy change per unit mass and $\mathrm{M}$ is the mass of the sample. The values of $\Delta \mathrm{H}_{\mathrm{c}}$ for the investigated glassy samples at heating rate $15^{\circ} \mathrm{C} / \mathrm{min}$ is shown in Table (2). The enthalpy release during the crystallization increases as the $\mathrm{S}$ content increased up to $3.22 \%$ indicating an increase in the glass stability for these compositions. However, as the $\mathrm{S}$ is further increased to $4.76 \%$ the enthalpy decreases indicating a decrease in the thermal stability of this compound.

The glass forming tendency is related to the chemical bonds that determine the structure and all the properties of a body in any state of aggregation. For chalcogenide glasses, chemical bonds with lone-pair electrons have a character of flexibility. This flexibility relies on the type, strength and concentration of possibly existing chemical bonds in the glass.

Hruby and Stourac [4] suggested an appropriate measure for the glass forming ability, which can be determined from DTA or DSC scan:

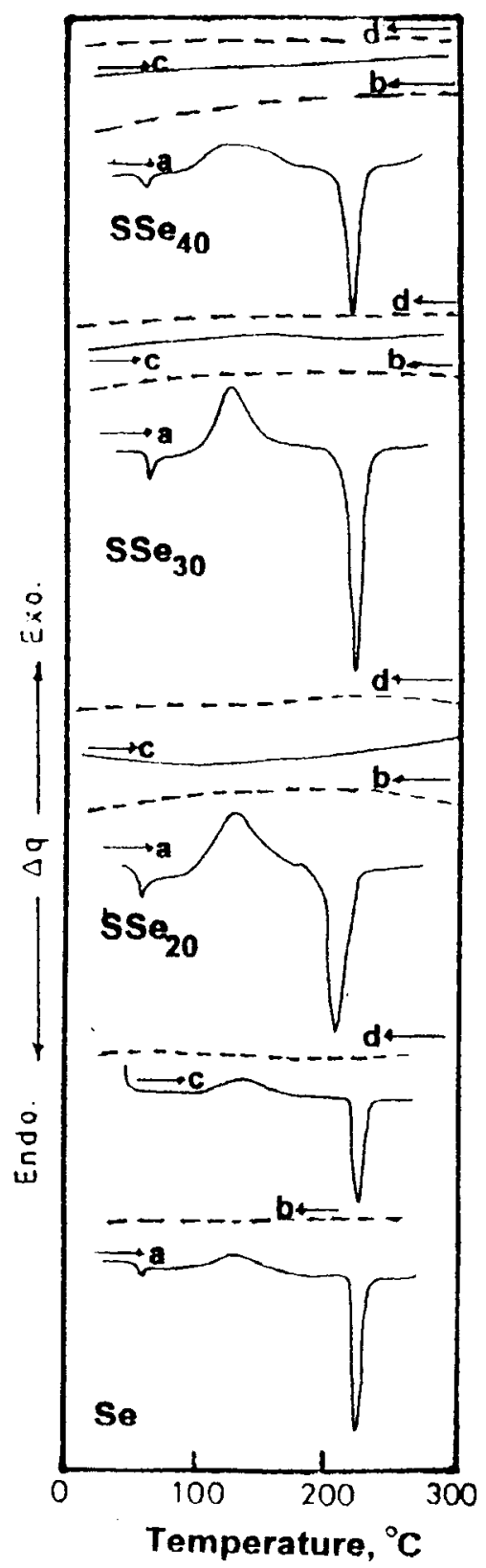

Fig.(1): DSC scans for the Investigated compositions during the two heating-cooling cycles.

$$
\mathrm{Kg}_{\mathrm{L}}=\left(\mathrm{T}_{\mathrm{c}}-\mathrm{T}_{\mathrm{g}}\right) /\left(\mathrm{T}_{\mathrm{m}}-\mathrm{T}_{\mathrm{c}}\right)
$$


where $T_{c}$ and $T_{m}$ represent the temperatures of the start of crystallization and melting, respectively. The value of $\mathrm{k}_{\mathrm{gL}}$ of $\mathrm{SSe}_{\mathrm{x}}$ glasses from their DSC scans at $15^{\circ} \mathrm{C} / \mathrm{min}$ are given in Table (2). This table shows that $\mathrm{kg}_{\mathrm{L}}>0.1$ for all investigated glasses, and it decreases with increasing $\mathrm{S}$ content.

Table (1)

Characteristic transition temperature of the investigated glassy composition at heating of rate $15 \mathrm{deg} / \mathrm{min}$..

\begin{tabular}{|c|c|c|c|}
\hline Composition & $\mathbf{T}_{\mathbf{g}},{ }^{\mathbf{0}} \mathbf{C}$ & $\mathbf{T}_{\mathbf{c}},{ }^{\mathbf{0}} \mathbf{C}$ & $\mathbf{T}_{\mathbf{m}},{ }^{\mathbf{0}} \mathbf{C}$ \\
\hline $\mathrm{Se}$ & 56 & 88.7 & 223.6 \\
$\mathrm{SSe}_{40}$ & 55 & 84 & 215.5 \\
$\mathrm{SSe}_{30}$ & 54 & 83 & 217.5 \\
$\mathrm{SSe}_{20}$ & 52 & 78.3 & 210.2 \\
\hline
\end{tabular}

Table (2)

Hardness, density, glass forming tendency and enthalpy of the investigated compositions..

\begin{tabular}{|c|c|c|c|c|c|}
\hline $\begin{array}{c}\text { Composit } \\
\text { ion }\end{array}$ & $\begin{array}{c}\text { Sulphur } \\
\text { Content \% }\end{array}$ & $\begin{array}{c}\mathbf{H a r d n e s s} \\
\mathbf{K g} / \mathbf{m m}^{2}\end{array}$ & $\begin{array}{c}\text { Density } \\
\mathbf{g m} / \mathbf{c m}^{3}\end{array}$ & $\mathbf{k}_{\mathbf{g L}}$ & $\mathbf{\Delta H}_{\mathbf{c}}, \mathbf{J} / \mathbf{g}$ \\
\hline $\mathrm{Se}$ & 0 & 28 & 4.40 & 0.242 & 21.95 \\
$\mathrm{SSe}_{40}$ & 2.44 & 41 & 4.20 & 0.221 & 47.00 \\
$\mathrm{SSe}_{30}$ & 3.22 & 32 & 4.12 & 0.215 & 63.18 \\
$\mathrm{SSe}_{20}$ & 4.76 & 30 & 4.04 & 0.199 & 41.77 \\
\hline
\end{tabular}

Heat capacity is one of the most basic thermal characteristics of matter. The information obtained from the heat capacity is fundamental to its thermodynamic description. DSC permits measurement of the specific heat of solids. Since the level of baseline in DSC is proportional to the heat capacity of the sample, specific heat can be measured by comparing the level of the baseline of a given sample with that of a standard materials with known specific heat, e.g. $\alpha \mathrm{Al}_{2} \mathrm{O}_{3}$.

The variation of specific heat $\mathrm{C}_{\mathrm{p}}$, of the investigated samples with temperature is shown in Fig. (2). It can be observed that $C_{p}$ shows a peak at $T_{g}$ i.e., $T_{g}$ is normally defined as the temperature onset of the step-wise increase in heat capacity during heating of the glassy materials. Also, it is seen that the effect of increasing $\mathrm{S}$ content in the examined samples generally increases the value of $\mathrm{C}_{\mathrm{p}}$ as well as shifts the peak values of $\mathrm{C}_{\mathrm{p}}$ towards the lower temperature. The increase in the value of the heat capacity of the investigated 
compositions at $\mathrm{T}_{\mathrm{g}}$ are similar to those observed for other chalcogenide glasses [5]. Such increase is due to configuration degrees of freedom which the material posses in the supercoold liquid state and the breakdown of the thermodynamic equilibrium of the system [6,7].

Selenium and sulfur, as well as their binary alloys, form the ring-chain structural model. Analysis of Raman spectra for S-Se alloys indicated the formation of equilibrium mixtures of linear polymer molecules and eightmembers link [8]. Furthermore, theoretical analysis based on equilibrium in the liquid phase suggests that the addition of sulfur reduces the concentration of atoms in chains, as well as the length of the chain leading to a decrease in $T_{g}$ [9]. Henceforth, the values of the corresponding $\mathrm{C}_{\mathrm{p}}$ tends to shift towards low temperature.

Table (2) shows that the density (determined by the hydrostatic method within \pm 0.05 $0.1 \%$ ) decreasing from 4.4 to 4.04 $\mathrm{gm} / \mathrm{cm}^{3}$ with increasing $\mathrm{S}$ content. The atomic weights of Se and $\mathrm{S}$ are 78.96 and 32.06, respectively, and their respective atomic radii are 1.15 and $1.03 \AA$. That is the atomic weight as well as the atomic volume

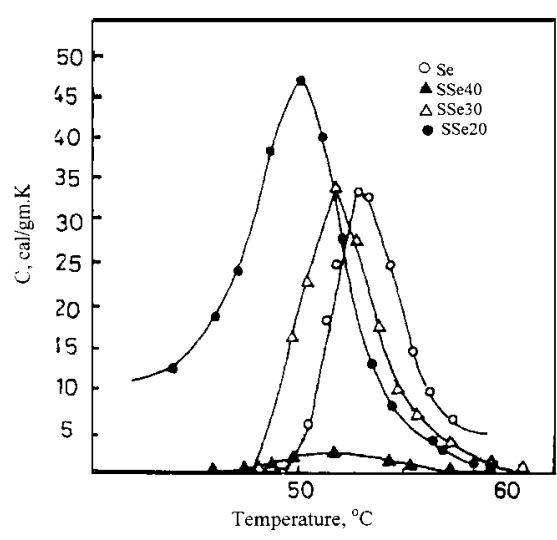

Fig.(2): Polt of specific heat versus temp.

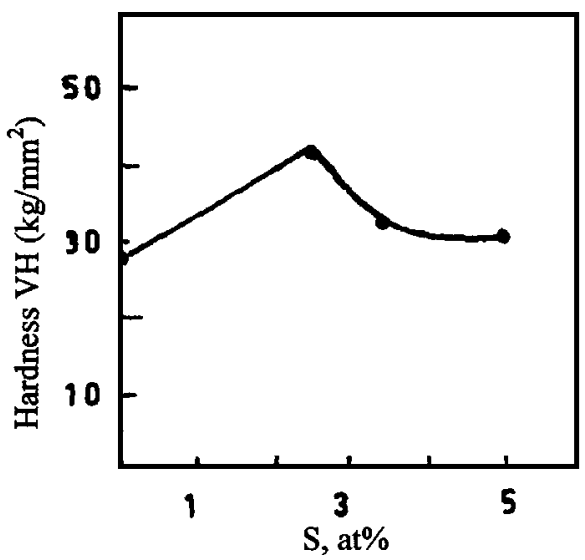

Fig. (3): Plot of hardness versus sulphur content of $\mathrm{S}$ are smaller than those of $\mathrm{Se}$ which means that the molecular weight of the glasses decrease by increasing $\mathrm{S}$ $\%$ content, which accounts for the observed decrease of density with increasing S content.

The hardness of the investig-ated compositions are shown in Table (2), as a function of atomic percent of S. As can be observed from Fig. (3), on the initial introduction of $\mathrm{S}$ into the compound there is an increase in the hardness. However, as the content of S increases beyond the value of 2.44 there is a clear 
reduction in the hardness indicating a decrease in the strength of the compounds.

\section{2-Heating-cooling cyclic scanning :}

The effect of two consecutive heating-cooling cycles covering the temperature range $T_{\mathrm{g}}-\mathrm{T}_{\mathrm{m}}$ were examined, using DSC curves for the investigated glasses. The normal procedure for the DSC cyclic scan was: (a) To raise the temperature to $280^{\circ} \mathrm{C}$ at a heating rate of $15 \mathrm{deg}$. $\min ^{-1}$.(b) To lower the temperature to $20^{\circ} \mathrm{C}$ at a cooling rate $\approx 15 \mathrm{deg} \cdot \mathrm{min}^{-1}$. (c) To repeat steps (a) and (d).

The investigation of the two consecutive cyclic scans of the examined glasses indicated the following behaviors (Fig. (1)):

1- For pure Se, the DSC traces show $T_{g}, T_{c}$, and $T_{m}$ peaks on run (a). On run

(b) during cooling cycle, no features of interest were observed. During second heating cycle, there were no observations detected relative to run (a), except that the absence of $\mathrm{T}_{\mathrm{g}}$. In the second cooling cycle, no features of interest are observed, as in run (b).

2- For the compositions $\mathrm{SSe}_{40}, \mathrm{SSe}_{30}$ and $\mathrm{SSe}_{20}$, the DSC traces show $\mathrm{T}_{\mathrm{g}}, \mathrm{T}_{\mathrm{c}}$, and $\mathrm{T}_{\mathrm{m}}$ peaks on run (a). During 1st and 2nd cooling cycle, no features of interest were observed.

During the second heating one can notice the disappearance of $T_{g}, T_{c}$ and $T_{m}$, which is due to the form of the material (before run (a) the material was in powder form, but before run (c) the material is in a bulk ingot form, because of melting). The crystallization can occur more readily in a powdered glass than in a large solid pieces [4].

It is known that chalcogenide glasses exhibit threshold and memory switching. The glasses which exhibits no exothermic peaks in cooling runs, display very little tendency to crystallize and consequently appear to be of threshold switching type. The glasses which exhibit an exothermic crystallization peak in the cooling runs, have a high tendency to crystallize, and hence may exhibit memory type switching [9]. In our case the experimental results indicate that the investigated samples are of threshold type.

\section{3- Kinetic evaluation of crystallization:}

Kinetics of the crystallization processes of the glasses compositions $\mathrm{SSe}_{\mathrm{x}}$ have been investigated using single-scan technique through an improved signal DSC model. Previous studies have shown that this model can be applied to study thermally activated crystallization in amorphous chalcogenide semiconductors [10-12]. 
The volume fraction $\mathrm{A}(\mathrm{t})$ transformed after a given time $\mathrm{t}$ (or temperature $\mathrm{T}$ ) can be calculated from the thermograph using the equation [13], $\alpha(\mathrm{t})=\mathrm{A}(\mathrm{t}) / \mathrm{A}$ where $\mathrm{A}$ is the total peak area, and $\mathrm{A}(\mathrm{t})$ the area under the peak up to the time $t$ (or temperature $\mathrm{T}$ ). An estimation of the complex activation energy of crystallization E can be made using Coats-Redform-Sestak method $[13,14]$. This means that the kinetic equation is

$$
\mathrm{n}^{-1} \ln [-\ln (1-\alpha)]-2 \ln \mathrm{T}=\ln \left(\mathrm{k}_{\mathrm{o}} \mathrm{R} / \mathrm{nE} \phi\right)-\mathrm{E} / \mathrm{RT}
$$

where $\mathrm{k}_{\mathrm{o}}$ is the rate constant, $\mathrm{n}$ the order of crystallization, $\phi$ is the heating rate and $E$ is the activation energy. If $n$ is known, a plot of $n^{-1} \ln [-\ln (1-\alpha)]-2 \ln T$ versus $1 /$ T yields a straight line, whose slope E. According to Satava and Sestak [15 \&14] assumptions the term $2 \operatorname{lnT}$ can be neglected and equation (5) becomes:

$$
\mathrm{n}^{-1} \ln [-\ln (1-\alpha)]=\ln \left(\mathrm{k}_{\mathrm{o}} \mathrm{R} / \mathrm{nE} \phi\right)-\mathrm{E} / \mathrm{RT}
$$

In case $\mathrm{n}$ is unknown, a plot of $\mathrm{n}^{-1} \ln [-\ln (1-\alpha)] \mathrm{vs} 1 / \mathrm{T}$ is carried out with $\mathrm{n}=1,2,3 \& 4$ to select the value of $\mathrm{n}$ that gives the best linear relation. In our case the proper value of $n$ was found to be one. The typical plots of $\ln [-\ln (1-\alpha)]$ versus 1/T to obtain E are shown in Fig. (4) for the investigated compositions. The figure shows that the plot yields straight line for both first and second peaks of the investigated compositions. In case of the glass $\mathrm{SSe}_{30}$ two distinct slopes can be noticed which indicates two different rates of crystallization. Table (3) gives the values of $\mathrm{E}$ for the investigated glasses. The data illustrate that, on the initial introduction of $\mathrm{S}$ into Se there is a decrease in $\mathrm{E}$ from 23.36 $\mathrm{Kcal} / \mathrm{mole}$ (for Se) to $16.17 \mathrm{Kcal} / \mathrm{mole}$ (for $\mathrm{SSe}_{30}$ ). However, as the $\mathrm{S}$ content increases up to $4.76 \%$ there is an increase in E. This decrease may be attributed to the decrease of the number of crystallization centers with the addition of $S$ to Se as well as formation of long polymer chains due to $\lambda-v$ transition [16].

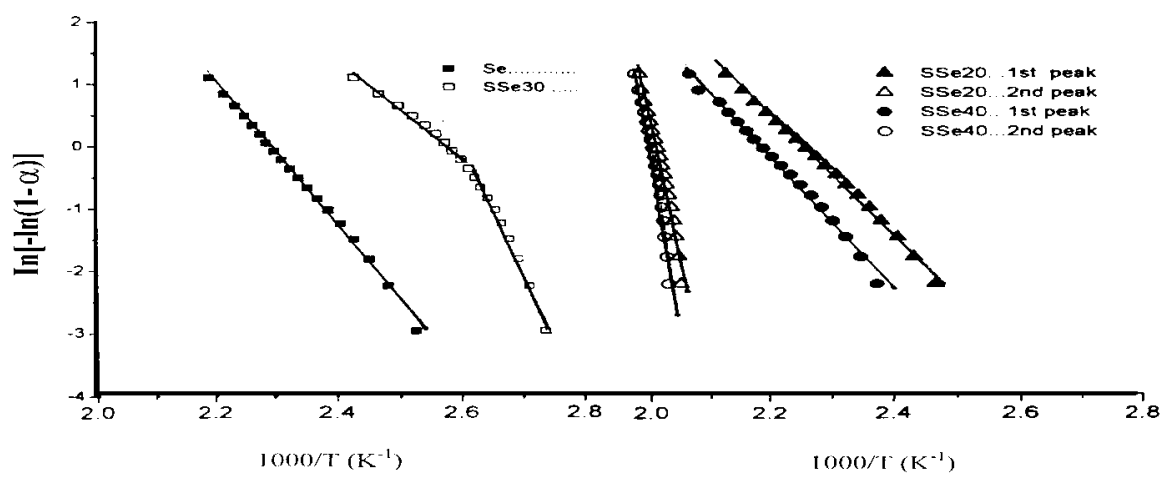

Fig.(4): Plots of $\ln [-\ln (1-\alpha)]$ versus $1 / \mathrm{T}$ for the investigated samples. 
Table (3)

Activation energy of crystallization of investigated glassy composition.

\begin{tabular}{|c|c|c|}
\hline \multirow{2}{*}{ Composition } & \multicolumn{2}{|c|}{ Activation Energy E, kcal/mol. } \\
\cline { 2 - 3 } & $\mathbf{1}^{\text {st }}$ peak & $\mathbf{2}^{\text {nd }}$ peak \\
\hline $\mathrm{Se}$ & 23.36 & -- \\
$\mathrm{SSe}_{40}$ & 20.68 & 116.7 \\
$\mathrm{SSe}_{30}$ & 16.17 & - \\
$\mathrm{SSe}_{20}$ & 19.98 & 88.23 \\
\hline
\end{tabular}

\section{Conclusion}

This study shows that the effect of adding $\mathrm{S}$ to Se leads to a decrease in the density as well as a decrease in the glass transition temperature due to the decrease in the chain length. The compositions has a threshold switching type as a result of the absence of exothermic peaks in the cooling runs. The thermal kinetic analysis shows that the crystallization process proceeds in one dimensional growth since $\mathrm{n}$ was shown to equal to one.

\section{References}

1. S.R. Ovshinsky, Phys. Rev. Letters 21 (1988) 1450.

2. L.A. Wahab, Proceeding of the Second International Conference (Science \& Development \& Enviroment) Cairo, p.215 (1997).

3. A.F. Maged, L.A. Wahab, I.A. El Kholy, J. Materials Science, 33(1998)3331.

4. A. Hruby and L. Stourac, Mat. Res. Bull., 6(1971) 465.

5. P.L. NaRasimham, A. Giridhar, and Sudha Mahadevan, J. Non. Cryst. Solids, 43 (1981) 301.

6. M.H. Cohen and G.S. Grest, Phys. Rev. B20 (1979) 1077.

7. C.A. Angell and W. Sichina, Ann, New York Acad. Sci., 53 (1976) 279.

8. J. Schotmiller, M. Tabak, G. Lucovsky and A. Ward, J. Non Cryst. Solids, $4(1970) 80$.

9. N.F. Mott and E.A. Davis, Electronic processes in Non Crystalline materials. Clarendon Press (Oxford, 1971) Ch. 10.

10. M.F. Kotkata, M.H. El Fouly, A.Z. El Behay and L.A. Wahab Mat. Sci., Eng.1, 60 (1983) 163. 
11. M.F. Kotkata, M.H. El Fouly, and M.B. El Den, Latin American J. Metallurgy and Materials, 5 (1985).

12. L.A. Wahab and S.A. Fayek, Solid State Communication 100 (1996) 345.

13. A.W. Coats and J.P. Redform, Nature 201 (1964) 68.

14. J. Sestak, Phys. Chem. Glasses 15 (1974) 137.

15. V. Satava, Thermochim. Acta 2 (1971) 423.

16.A. Eisenberg and A.V. Tobolsky, J. Polymer Science, 16 (1960). 